\title{
A construção do conceito de caboclo como demarcador social de inferioridade no sul do Brasil
}

\author{
Taiza Gabriela Zanatta Crestani ${ }^{1}$ \\ Silvio Antonio Colognese ${ }^{2}$ \\ Paulo Ricardo Bavaresco ${ }^{3}$
}

\begin{abstract}
Resumo: A construção social do conceito de "caboclo" está relacionada aos processos de erradicação do trabalho escravo e de promoção da imigração europeia para o Brasil. Tratase de uma nomenclatura criada para dar conta da disseminação da "mistura de raças" cujas consequências levam ao fortalecimento dos estereótipos acerca da população mestiça brasileira. Caboclo surge como um termo de demarcação social que prioriza certas características físicas (mestiço de branco e índio, de pele acobreada e cabelo liso) e raciais (raça híbrida, inferior e degenerada). Posteriormente, as pesquisas empíricas desenvolvidas por Antropólogos e Sociólogos permitiram superar esta construção inicial, agregando fatores de classe, posição social, localização geográfica e sobretudo étnicos. Com isso, começaram a se evidenciar variações de sentido do termo caboclo. No entanto, antes de denotar uma condição étnicoracial, o termo caboclo é uma formação discursiva elaborada para inferiorizar um grupo de indivíduos no processo relacional e contrastante da construção das identidades - algo que fica evidente na região Sul do Brasil, influenciada pelos ideais progressistas característicos da política de colonização.
\end{abstract}

Palavras-Chave: Caboclo; Inferioridade; Sul do Brasil.

1 Mestra em Ciências Sociais pela UNIOESTE, Campus de Toledo. Docente do curso de Psicologia da UNOESC, Campus de São Miguel do Oeste (SC) e Pinhalzinho (SC). http:/ / orcid.org/0000-0002-2584-9487

2 Doutor em Sociologia pela UFRGS - Universidade Federal do Rio Grande do Sul, Porto Alegre (RS). Docente Efetivo da UNIOESTE - Universidade Estadual do Oeste do Paraná, Campus de Toledo (PR). http://orcid. org/0000-0003-0609-5066

3 Doutor em Ciências Sociais pela UNISINOS - Universidade do Vale do Rio dos Sinos (2010). Professor titular da UNOESC - Universidade do Oeste de Santa Catarina, Campus de São Miguel do Oeste (SC). http:// orcid.org/0000-0002-7296-3290 


\title{
The construction of the concept of caboclo as a social marker of inferiority in southern Brazil
}

\begin{abstract}
The social construct of the concept of "caboclo" is related to processes of slave work eradication and promotion of European migration to Brazil. It is a term created to deal with the "mixture of races", whose consequences led to the strengthening of stereotypes towards the Brazilian population of mixed ancestry. The term caboclo comes as a social indicator that prioritizes certain physical (mixed white and indigenous ancestry, coppercolored skin, and straight hair) and racial (hybrid, inferior and degenerated race) traits. Later, empirical work developed by Anthropologists and Sociologists allowed overcoming this initial construction, aggregating factors of class, social position, geographic location and especially ethnicity. Thus, variations in the sense of the term caboclo started to be observed. However, before indicating a ethnical-racial condition, the term caboclo is a discursive formation elaborated to undermine a group of individuals in the relational and contrasting process of building identities - which is evident in the South region of Brazil, influenced by progressist ideals that are characteristic of colonization policies.
\end{abstract}

keywords: Caboclo; Inferiority; southern Brazil. 


\section{A gênese do conceito de caboclo no Brasil: um breve resgate}

Pressionado pelo parlamento inglês, em meados do século XIX, o Império Brasileiro começa a adotar medidas jurídicas para erradicar o trabalho escravo. A promulgação da Lei Bill Aberdeen, que proibia o tráfico negreiro no Oceano Atlântico, teve grande impacto sobre as terras brasileiras, já que as fazendas de café localizadas nas províncias de São Paulo, Minas Gerais e Rio de Janeiro eram sustentadas até o momento por mão de obra escrava (GASPARETTOO JUNIOR, 2013).

Mesmo que os grandes latifundiários se opusessem ao fim da escravatura, em 1850, Dom Pedro sanciona a Lei Eusébio de Queiroz, vedando o tráfico de negros para os confins do Brasil. Entretanto, esta iniciativa de caráter abolicionista (interpretada como o primeiro passo para o desenvolvimento das ideias emancipatórias), na realidade foi uma estratégia de defesa adotada pelo Império para prevenir um possível confronto armado com a Inglaterra - que incentivava a imigração de trabalhadores livres (GONÇALVES, 2007; CERVO; BUENO 2010; OLIVEIRA 2017; MENDES, 2009).

Paradoxalmente, na medida em que o tráfico externo de africanos para o Brasil foi impossibilitado, intensificou-se o tráfico interprovincial e intraprovincial (FLAUSINO, 2006). A dura jornada laboriosa somada à dificuldade de repor trabalhadores (devido ao alto preço exigido pelos traficantes ilegais), ocasionou excessivo e rápido desgaste da mão de obra negra (LIMA FILHO, 2020). Em consonância, no cenário criado a partir das décadas de 1870 e 1880 (especialmente a partir da vulgarização da Lei Áurea em 1888 e com a anunciação do fim do Regime Monárquico em 1889), justificava-se a necessidade da imigração de estrangeiros (FERREIRA; FERNANDES; REIS, 2010).

Como resultado, a fachada do país estava sendo renovada. Com a vinda dos imigrantes europeus, considerados autênticos agentes do progresso e da civilização, almejava-se forjar uma população identificada com uma ideia de pátria brasileira que rejeitasse qualquer menção à heterogenia. O primeiro passo era desqualificar o trabalho assalariado dos nativos e, em seguida, exacerbar as qualidades dos estrangeiros. Assim, foram estabelecidas as polaridades que serviram de parâmetro para o delineamento de um perfil de habitante ideal (HOFBAUER, 1999; 2003).

No início do século XX, alguns autores influenciados pelas teorias científicas raciais marcadamente evolucionistas e eugenistas que estavam em voga nos Estados Unidos, tal como é o caso de Nina Rodrigues, Sylvio Romero, Oliveira Vianna e Euclides da Cunha, contribuíram para a implementação do projeto imigrantista (ORTIZ, 2006; COSTA 2009). Suas propostas legitimaram a projeção da sociedade brasileira como um sonho de pureza, já que tentavam criar um senso de nacionalidade pautado na uniformidade, que foi além da radicalização da fórmula romântica de nação, representando uma nova concepção pautada em conceitos arbitrários de verdade (ARAÚJO, BARBOSA 2016).

Em consonância, investir na política do branqueamento significava uma esperança de despir a nação brasileira dos elementos negros e ameríndios (HOFBAUER, 1999). Acreditava-se que, em torno de um século depois da entrada massiva de imigrantes provenientes da Europa no Brasil, o mestiço branqueado passaria a predominar no cenário nacional e isso asseguraria o pleno desenvolvimento do país.

As discussões em torno da miscigenação vigentes na época tangenciavam o debate acerca dos "atributos permanentes das raças particulares"; perguntavam-se os estudiosos da causa, se o meio ambiente, a educação, o sentimento público, as condições econômicas e 
sociais poderiam contribuir para modificar heranças antropológicas, e sobre a possibilidade das diferenças físicas corresponderem às diferenças mentais (SPILLER 1911 apud SOUZA; SANTOS, 2012). O que alimentava o eurocentrismo nestes embates era justamente a descrença no fato de que o cruzamento do homem branco com a mulher negra (ou vice-versa) pudesse resultar no enegrecimento da população: acreditava-se piamente na primazia do gene ariano, e a mestiçagem, nesta linha de raciocínio, era considerada uma condição transitória que viria a desaparecer (SKIDMORE, 2012; SANTOS; SILVA, 2018).

Não tão puro como o branco, nem tão contrafeito quanto o negro, o mestiço nascido no Brasil representava uma síntese da categoria dominante e da categoria dominada sem tampouco ser reconhecido enquanto integrante de uma ou de outra. Destarte, conforme aponta Darcy Ribeiro, é bem provável que ele comece a surgir e perceber a si, mais através da percepção de estranheza que provocava no imigrante do que por sua identificação como membro das comunidades que estavam começando a se estruturar. Nas palavras do autor, o brasileiro:

Naquela busca de sua própria identidade, talvez até se desgostasse da ideia de não ser europeu, por considerar, ele também, como subalterno tudo que era nativo ou negro. Mesmo o filho de pais brancos nascido no Brasil, mazombo, ocupando em sua própria sociedade uma posição inferior com respeito aos que vinham da metrópole, se vexava muito da sua condição de filho da terra, recusando o tratamento de nativo e discriminando o brasilíndio mameluco ao considerá-lo como índio. O primeiro brasileiro consciente de si foi, talvez, o mameluco, esse brasilíndio mestiço na carne e no espírito, que não podendo identificar-se com os que foram seus ancestrais americanos - que ele desprezava -, nem com os europeus - que o desprezavam -, e sendo objeto de mofa dos reinóis e dos luso-nativos, via-se condenado à pretensão de ser o que não era nem existia [...]. Através dessas oposições e de um persistente esforço de elaboração de sua própria imagem e consciência como correspondentes a uma entidade étnico-cultural nova, é que surge, pouco a pouco, e ganha corpo a brasilianidade (RIBEIRO 2015, p.96-97).

A concretização do objetivo de implantar uma europeidade aos trópicos passa a ser prejudicada na medida em que a tese do branqueamento começa a evidenciar sinais de fracasso. Conforme podemos concluir com base nas considerações do autor supracitado, a não ascensão imediata dos nativos aos desígnios estrangeiros foi uma surpresa - pois jamais havia sido elencada a hipótese de que o nativo brasileiro (visto como projeto inacabado) seria capaz de captar o sentimento de estranhamento diante do outro europeu (que deveria lhe servir de modelo) e, a partir deste ato de reconhecimento, tomar consciência de si e de sua diferença.

Isso demonstra como a questão da identidade, tal qual apresentada pelos defensores do projeto imigrantista, já nasce ancorada na ideologia da aculturação, perspectiva assumida também pela Historiografia Oficial brasileira, que marginalizou a contribuição dos povos colonizados e vangloriou a trajetória dos colonizadores, respeitados como grandes líderes e heróis.

É somente a partir de 1933, em decorrência da publicação de Casa Grande e Senz̧ala, que ocorre uma mudança significativa na forma de analisar a contribuição dos subalternos. Gilberto Freyre contribui, neste sentido, para frisar as vantagens de ser mestiço, cunhando o termo meta-raça para referir-se a este sujeito, testemunha "fraternal" da relação do homem branco com o negro e o índio (COSTA, 2002). Daí origina-se o mito da democracia racial, em que a mestiçagem, enquanto característica predominante dos nascidos no Brasil, passa a ser considerada um vetor de homogeneização (SKIDMORE, 2012). 
Todavia, a instauração desta imagem do povo brasileiro enquanto "povo miscigenado", destaca Chauí (2000), acaba resolvendo apenas no plano imaginário uma tensão que produz efeitos bastante concretos. Conforme explica a autora, é com base nesta representação que muitos indivíduos batem no peito para declarar que se sentem orgulhosos da pátria-mãe (alegando ser o Brasil um país multicultural e carente de preconceito) e, ao mesmo tempo, acusam os índios de serem ignorantes, os negros de serem rebeldes, e os nordestinos de serem atrasados.

Em consonância, destaca Florestan Fernandes (2008), o mito da democracia racial, desde o momento de sua emergência, objetivou isentar o branco

de qualquer obrigação, responsabilidade ou solidariedade morais, de alcance social e de natureza coletiva, perante os efeitos sociopáticos da espoliação abolicionista e da deterioração progressiva da situação socioeconômica do negro e do mulato", colaborando para recuperar "a técnica de focalizar e avaliar as relações entre negros e brancos através de exterioridades ou aparências dos ajustamentos raciais, forjando uma consciência falsa (FERNANDES, 2008, p.311).

Pode-se conjecturar, por conseguinte, que a tentativa de incutir na população um sentimento de unidade e coesão social através da imposição de formações discursivas que gozavam de status privilegiado condiciona a aceitação do caráter normativo da diversidade a partir da negação da diferença ${ }^{4}$. Fica, assim, explícito o perigo de contar uma história e considerá-la como a exclusiva versão dos fatos e acontecimentos devido ao seu "alvará" institucional. Como bem definiu Chimamanda Ngozi Adichie (2019), escritora nigeriana, o poder do discurso provém da sua capacidade de perpetuar-se enquanto parâmetro de referência. Em suas palavras: o ato de não só contar a história de outra pessoa (ou grupo), mas de privilegiar certos aspectos ao fazê-lo (no intuito de torná-la única e definitiva), é um ato que ameaça os próprios sujeitos a que esta história se refere - retirando-lhes a possibilidade da reformulação. James Clifford (2002), ao propor a discussão do exercício da autoridade etnográfica, bem como Jacques Le-Goff (1990) ao ressaltar o valor da história oral, nos advertem constantemente a este respeito, evidenciando como a ciência também pode contribuir para a reprodução e fortalecimento de estigmas.

Analisando tais considerações, percebe-se que a disseminação do argumento da "mistura de raças" contribuiu para a criação de nomenclaturas essencialmente pejorativas. Como exemplo, podemos citar as expressões: mulato, cafuzo e caboclo - frequentemente utilizadas para especificar a "tipagem" dos mestiços, e todas lexicalmente contaminadas, tal qual é possível observar a partir de um breve resgate das suas origens etimológicas.

\section{A definição do termo caboclo na região Sul do Brasil: questionamentos necessários}

Especificamente no que tange ao surgimento e ao emprego do termo caboclo enquanto demarcador social, ao final do século XIX e início do século XX, nota-se a priorização de características físicas: mestiço de branco com índio, índio aculturado de pele acobreada e cabelo liso (FERREIRA apud WITKOSKI, 2010; ZARTH, 1998) e raciais (raça híbrida, raça inferior, raça degenerada). Destarte, entre 1960 e 1980, supõe-se que é objetivando refutar esta ideia inicial de "caboclo", cunhada num determinismo biológico, que antropólogos e sociólogos se debruçam à sua compreensão, privilegiando-se dados provenientes de pesquisa de campo.

\footnotetext{
É justamente isso o que caracteriza a democracia racial enquanto mito.
} 
Através do contato com indivíduos enquadrados (a priori) na categoria caboclo, concepções de classe, posição social e localização geográfica vão sendo acopladas às definições inaugurais. Quando o elemento étnico aparece neste processo de síntese, as variações de sentido no uso do termo começam a se evidenciar. Especialmente, tal constatação pode ser verificada a partir da contribuição de alguns autores cujas pesquisas tangenciam os processos de construção da identidade do caboclo sulista. Segue-se, então um pequeno panorama:

- Em O povo brasileiro, originalmente publicado na década de 1970, Darcy Ribeiro destaca que, enquanto os caboclos amazônicos são definidos como povos que fazem uso de uma tecnologia adaptativa, essencialmente indígena, conservada e transmitida, cujo estilo de vida expressa uma variedade cultural particular não tribal, os caboclos sulistas, em contrapartida, são caracterizados como excedentes do sistema latifundiário que regrediram à pobreza.

- Caio Prado Júnior (1981), por sua vez, caracteriza o caboclo como o trabalhador livre, brasileiro, que prestava serviço aos fazendeiros. Para o autor, nas fazendas metropolitanas, aos caboclos eram dadas ordens relacionadas ao cultivo de alimentos destinados à exportação, tais como cana-de-açúcar e café, enquanto que nas fazendas localizadas ao sul do país, prestam serviços relacionados à criação de animais e de manutenção ao administrador local.

- Kalervo Oberg (1960), antropólogo canadense que visitou os estados do Paraná e do Mato Grosso do Sul nos anos de 1960, faz menção à cultura cabocla como um substrato de vida campesina marginal, com baixo padrão de vida, formada por trabalhadores rurais (roceiros, pescadores, lavradores).

- Arlene Renk (1991; 1995; 1999; 2004; 2006), Jaci Poli (1991), Patrício Reichert (2008), Paulo Pinheiro Machado (2004), que estudaram a ocupação cabocla no Extremo Oeste de Santa Catarina, consideram a prática da extração da erva-mate como um ofício quase que exclusivo dos caboclos (povo relegado a segundo plano pelos colonos devido à sua baixa capacidade de expressão econômica, desbravadores de sertões, adeptos de uma filosofia de vida alheia à lógica capitalista e cumulativa). De modo complementar, cabe mencionar Marli Auras (2001), autora que valoriza as atividades de produção na definição do caboclo à semelhança dos autores supracitados, mas enfatiza as práticas culturais e crenças religiosas no entendimento dos processos de afiliação grupal durante a Guerra do Contestado.

- Roberto Pocai Filho (2007; 2011; 2014), Giralda Seyferth (2000; 2002) e Moacir Motta da Silva (2012) descrevem os caboclos que vieram a se estabelecer no sudoeste do estado do Paraná como: camponeses pobres que, independentemente de raça, cor (branca, parda, negra ou amarela), buscavam a (re)inserção social através do vínculo de trabalho. Também nesta linha, destacam-se os estudos de Ricardo Abramovay (1981), Ruy Wachowicz (1981; 1982; 1985; 2001) e Mondardo $(2007 ; 2008 ; 2010)$ que compreendem o perfil caboclo a partir do seu modo de levar a vida, sob um sistema específico de ocupação/posse da terra. 
Nestas definições, pode-se perceber que a marginalização é o argumento sobressaliente, evidenciando que o significado do termo reflete uma formação discursiva, outrora elaborada por um determinado grupo de indivíduos para inferiorizar outro. Este jogo de oposição, de inclusão e exclusão que se origina a partir da elaboração de categoriais de "nós" e "outros", "eu" e "eles", durante as experiências de encontro e confronto entre culturas, expressa a dinâmica contrastante das formações identitárias, visto que é nas situações limítrofes que os grupos tendem a resgatar e frisar certas características (ou mecanismos de interação) em prol de defender, legitimar, ou expressar a ideia que construíram a respeito de si (BARTH, 2011; SEYFERTH, 2000). Tal configuração socioeconômica e política, na perspectiva de Seyferth (2000), evidencia que a organização comunitária passou a ser um recurso simbólico poderoso para o fortalecimento do senso de pertencimento e/ou identificação a uma etnia.

Na região sulina do Brasil, vale destacar que o conceito de colono passa a ser considerado como sinônimo de imigrante e de pequeno proprietário, enquanto o conceito de caboclo é considerado sinônimo de nativo brasileiro, posseiro e ex-posseiro, justificando-se a necessidade de resgatar alguns marcos históricos fundamentais para o entendimento destas equivalências.

Quando o direito de propriedade passa a prevalecer sobre o direito de posse a partir da promulgação da Lei de Terras em 1850, os nativos brasileiros passam a competir em condições desfavoráveis com os migrantes italianos, alemães e poloneses, que, sob o amparo de iniciativas governamentais, começaram a se estabelecer na região (GEHLEN, 1998). Especificamente na década de 1930, na Era Vargas, dá-se início à campanha "Marcha para o Oeste", que incentivava diretamente os povos sulistas a fixar suas residências no Sudoeste do estado do Paraná e Extremo Oeste do estado de Santa Catarina.

Esta iniciativa civilizatória que visava preencher os chamados "vazios demográficos" (ZATTA, 2016) contava com a parceria de companhias colonizadoras, que auxiliavam na divulgação de propagandas sobre a fertilidade e a abundância das novas terras; investiu-se na propaganda para atrair imigrantes europeus, na transferência até as áreas de ocupação, na concessão de auxílios diversos e na distribuição de lotes aos imigrantes (VENDRAME, 2018). Todavia, subjacente à gentil preocupação de despertar o sentimento de familiaridade no europeu, reinava uma política agressiva cujo lema estava calcado numa lógica de merecimento fundamentalmente arbitrária: "boa terra para boa gente" (RENK,1995).

A qualidade "boa" estava, porém, ausente na população que anteriormente havia se estabelecido em meio às matas araucárias, composta por agregados das fazendas dos coronéis, ex-operários demitidos logo após o término das estradas de ferro, sem terras, ervateiros e dezenas de pequenos proprietários banidos de seus pinheirais (QUEIROZ, 1966, apud FEUDHAULS, 2013). Estes formavam, aos olhos dos estrangeiros, exatamente um protótipo daquilo que se deveria evitar/aniquilar.

Como resultado, fortalecem-se entraves simbólicos que delineiam as fronteiras de exclusão, enaltecendo as diferenças entre os colonos (indivíduos "de ascendência", com maior poder de impor a sua representação de mundo), e os nativos brasileiros (os "sem origem"), consequentemente reduzidos à condição de minoria (RENK, 1995; 2006). Sem capital monetário para deixarem de ser posseiros e se transformarem em proprietários, a alternativa que restou aos caboclos foi a habitação de terras inóspitas, devolutas.

De modo complementar, devido à compra de terras ser uma possibilidade extremamente remota aos caboclos, estes buscavam outras oportunidades de ascensão fazendo uso dos espaços das cidades, desenvolvendo atividades comerciais (DAL PIVA, 2019). Especificamente no cenário 
sulino, a produção da erva-mate representou um importante nicho de intercâmbio, propiciando aos caboclos a aquisição de produtos de segunda ordem. Nesta vertente, amparado em " $O$ significado histórico do levante armado dos colonos do Sudoeste do Paraná ocorrido em 1957’, de autoria de Lindomar Wessler Boneti (1997), Mondardo (2008) argumenta que após a chegada expressiva dos imigrantes italianos, alemães e poloneses no cenário regional, os caboclos constroem pequenas bodegas - chamadas "armazéns" - voltadas tanto à venda quanto à compra de produtos, onde elementos agrícolas eram negociados pelos caboclos para a aquisição de outros.

Verifica-se, assim, a existência de pontos de interlocução numa proposta de influência mútua entre os grupos étnicos que, ao utilizarem os espaços comerciais com o propósito de consumir produtos, inevitavelmente trocavam saberes e experiências de vida, crenças e valores, isto é, inevitavelmente consumiam práticas que transcendiam o labor. Porém, informações historiográficas nos levam a constatar que as implicações socioculturais dos grupos subalternizados no estilo de vida dos grupos dominantes foram, por parte dos últimos, veementemente negadas. Para tanto, um dos recursos indispensáveis foram os discursos oficiais e institucionalizados, marcadamente eurocêntricos.

Ampliando o escopo, destaca Boyer (1999, p.43) que "no Brasil inteiro, quando se fala em caboclos, pensa-se em mestiços de índios, instalados na beira dos rios, vivendo da pesca e da colheita, de temperamento preguiçoso e desconfiado" - deixando implícita a relação que subsidia esta adjetivação. Seguindo as trilhas de Robert Castel (1998), autor que se debruça a analisar os efeitos das propostas de cristalização "dos outros" engendradas pelos grupos dominantes, vale, pois, questionar: se os caboclos são assim categorizados, o são em relação a quem e com que propósito?

Basicamente, esta é a reflexão e é apontada por Lima (2009) cujas pesquisas centram-se na região da Amazônia, mas permitem a chegada de considerações mais gerais. De acordo com o seu ponto de vista, o termo caboclo é usado na literatura acadêmica, em grande escala, para fazer referência direta aos pequenos produtores rurais de ocupação histórica; já no discurso coloquial, "a definição da categoria social caboclo é complexa, ambígua e está associada a um estereótipo negativo, frequentemente utilizada para distinguir os habitantes tradicionais dos imigrantes recém-chegados".

A grande questão é que ambas as acepções de caboclo mencionadas constituem categorias de classificação social empregadas majoritariamente por pessoas que não se incluem na sua definição (LIMA, 2009). Nesta perspectiva, salienta-se a necessidade do desenvolvimento de pesquisas que visem à desconstrução de rótulos associados ao termo, os quais podem apresentar barreiras significativas para a mobilidade de alguns grupos sociais, justamente por estarem assentadas em oposições, conforme aponta Richard Pace (2006).

Ao problematizar a autoridade da e na escrita acadêmica, apontando indícios de abuso científico do termo caboclo, o autor acima referenciado destaca:

Quando um grupo não é bem estudado ou compreendido, as chances de estereotipálo e de uma aceitação inquestionável das denominações pejorativas pela comunidade acadêmica aparecem com maior probabilidade. Uma vez que, até recentemente, os "caboclos" não têm sido altamente valorizados como sujeitos etnográficos pelos brasileiros ou estrangeiros [...] mas vistos meramente como índios sem cultura, ou camponeses que se tornaram empecilhos ao desenvolvimento social e econômico da região, [...] há a persistência de nomes depreciativos (PACE, 2006, p.87). 
Na sequência, Pace (2006) descreve alguns dos problemas verificados na representação do caboclo na ótica de pesquisadores da antropologia e ciências sociais. Um destes problemas é que o termo caboclo, salvo algumas exceções, compactua com a "tendenciosa perspectiva da classe média urbana”. Em suas palavras:

Sugere-se, talvez abusando da autoridade, que, para a população de classe média urbana, o uso do termo "caboclo" ajuda a separá-la, de forma temporal, espacial e social, dos habitantes das regiões rurais. Em certo sentido, introduz-se uma sequência evolutiva, na qual civilização "superior" e semisselvageria "inferior" são distanciadas [...]Por que os cientistas sociais deveriam identificar-se com a visão da classe média urbana, imitar seu vocabulário e ajudar a perpetuar, voluntária ou involuntariamente, as desigualdades entre as populações rurais e urbanas, através do estilo retórico ou da "cronopolítica"? Possivelmente porque seus colegas e pares são, inevitavelmente, membros da classe média urbana brasileira e a maior parte do diálogo e colaboração na pesquisa ocorre nesse mesmo âmbito e não no âmbito dos habitantes rurais [...] (PACE, 2006, p.87-88-89).

Em consonância, cabe referenciar Viveiros de Castro (2002) que, em seu emblemático texto "O nativo relativo", destaca a necessidade de os pesquisadores assumirem que o ponto de vista dos seus interlocutores, isto é, das pessoas com as quais dialoga no contexto da pesquisa de campo, tem de ser necessariamente considerado mais importante do que o seu próprio ponto de vista. Isso significa que buscar adequar os sujeitos em acepções previamente definidas, com as quais muitas vezes os pesquisadores percebem-se familiarizados e tomam como acabadas e prontas, é um equívoco tremendo. Aproximando tais reflexões à temática deste ensaio, frisa-se a necessidade de se entender especificidades dos grupos sociais, com base na cultura regional, para que a aplicabilidade e o propósito do termo caboclo sejam problematizados.

Como ponto de partida, podemos citar alguns questionamentos importantes, tais como: o que eu, na qualidade de pesquisador ou pesquisadora estou querendo dizer ao empregar o termo caboclo? Como entendo o local a que faço referência? Aonde pretendo chegar com esta demarcação? Quais os recursos que utilizo para delimitar esta categoria e quais as suas implicações "dentro" e "fora" da academia? Será que as pessoas às quais me refiro como caboclas reconhecem esta nomenclatura para falar de si? Se sim, quais os seus significados? Se não, por que não? E mais: como os grupos que a literatura descreve e aponta como caboclos gostariam de ser referenciados (quais os termos que fazem sentido para os sujeitos e são frequentemente empregados em suas narrativas identitárias)? Indagações deste caráter, que incitam a revisão conceitual e também a tomada de consciência do(s) ângulo(s) de análise assumido(s) pelos pesquisadores, são imprescindíveis para a superação do que Pace (2006) define como uso genérico do termo caboclo. São os interlocutores que dirão ao pesquisador se este termo é útil ou não. Provavelmente, já estejam nos dizendo há muitos anos - mas não os estamos ouvindo da forma como deveríamos (SPIVAK, 1988). 


\section{Referências}

ABRAMOVAY, R. Transformações na vida camponesa: o sudoeste do Paraná. Universidade de São Paulo. Dissertação (Mestrado). Filosofia, Letras e Ciências Humanas. São Paulo: 1981.

ADICHIE, C. N. O perigo da história única. Tradução: Júlia Romeo. São Paulo: Companhia das Letras, 2019.

ARAUJO, Gabriel Frias; BARBOSA, Agnaldo de Souza. Cultura e Identidade Nacional nos anos Vargas: Tensões e contradições da uma Cultura Oficial. Revista de Ciências do Estado. v. 1, n. 2, 2016. Disponível em: https://seer.ufmg.br/index.php/revice/article/view/3668. Acesso em: 19 out., 2020.

AURAS, M. Guerra do contestado: a organização da irmandade cabocla. 4. ed. Florianópolis: Ufsc, 2001.

BARTH, F. Grupos étnicos e suas fronteiras. In: POUTIGNAT, Philippe; STREIFF-FENART, Jocelyne. Teorias da etnicidade: seguido de grupos étnicos e suas fronteiras de Fredrik Barth. 2. ed. São Paulo: Ed da UNESP, 2011.

BONETI, L. W. O significado histórico do levante armado dos colonos do Sudoeste do Paraná ocorrido em 1957. $2^{a}$ ed. Editora UNIJUÍ: Ijuí, 1997.

BOYER, V. O pajé e o caboclo: de homem a entidade. Mana. Rio de Janeiro. v. 5, n. 1, p. 29-56. 1999. Disponível em: http://www.scielo.br/scielo.php?script=sci_arttext\&pi$\mathrm{d}=$ S0104-93131999000100002\&lng=pt\&nrm=iso. Acesso em: 12 out., 2020.

CASTEL, R. As metamorfoses da questão social: uma crônica do salário. Tradução de Iraci D. Poleti. Petrópolis: Vozes, 1998.

CASTRO, E. V. O nativo relativo. Mana. Rio de Janeiro. v. 8, n. 1, p. 113-148. 2002. Disponível em: http://www.scielo.br/scielo.php?script=sci_arttext\&pid=S0104-93132002000100

005\&lng=en\&nrm=isso. Acesso em: 10 out., 2020.

CERVO, A. L. BUENO, C. História da política exterior do Brasil. 3. ed. Brasília: Editora Universidade de Brasília, 2010.

CHAUÍ, M. Brasil: mito fundador e sociedade autoritária. São Paulo: Editora Fundação Perseu Abramo, 2000.

CLIFFORD, J. A experiência etnográfica: antropologia e literatura no século XX/ organizado por José Reginaldo Santos Gonçalves. 2. ed. Rio de Janeiro: Editora UFRJ, 2002.

COSTA, R, G. Mestiçagem, racialização e gênero. Sociologias. Porto Alegre. n. 21, p. 94120. 2009. Disponível em: http://www.scielo.br/scielo.php?script=sci_arttext\&pi$\mathrm{d}=\mathrm{S} 1517-45222009000100006 \& \operatorname{lng}=$ en\&nrm=iso. Acesso em: 12 out., 2020.

COSTA, S. A construção sociológica da raça no Brasil. Estud. afro-asiát. Rio de Janeiro. v. 24, n. 1, p. 35-61. 2002. Disponível em: http://www.scielo.br/scielo.php?script=sci _arttext\&pid=S0101-546X2002000100003\&lng=en\&nrm=iso. Acesso em: 22 set., 2020.

DAL PIVA, J. A categoria colono no relatório socioeconômico Toledo de Kalervo Oberg. Dissertação (Mestrado em Ciências Sociais) - Universidade Estadual do Oeste do Paraná. Toledo: 2019. 
FERNANDES, F. A integração do negro na sociedade de classes: o legado da raça branca. 5. ed. São Paulo: Globo, 2008, vol. I.

FERREIRA, G. N.; FERNANDES, M. F. L.; REIS, R. R. O Brasil em 1889: um país para consumo externo. Lua Nova. n.81, p.75-113. 2010. Disponível em: https://doi.org/10.1590/ S0102-64452010000300005. Acesso em: 15 ago. 2020.

FLAUSINO, C.C. Negócios da escravidão: tráfico interno de escravos em Mariana (1850-1886). Dissertação (Mestrado em História). Universidade Federal de Juíz de Fora. Juiz de Fora, 2006.

FELDHAUS, F. O conflito do contestado como espaço de representação do sagrado: dos monges ao ícone são João Maria .RA'E GA, v..27, p.204-233. 2013. Disponível em: <https://revistas.ufpr.br/raega/article/view/30423> Acesso em 30 Ago, 2020.

GASPARETTO JÚNIOR, A. Direitos sociais em perspectiva: seguridade, sociabilidade e identidade nas mutuais de imigrantes em Juiz de Fora (1872-1930). Dissertação (Mestrado em História). Universidade Federal de Juiz de Fora. Juíz de Fora: 2013.

GONCALVES, P. C. Escravos e imigrantes são o que importam: fornecimento e controle da mão de obra para a economia agroexportadora Oitocentista. Almanack. n.17. p.307361. 2017. Disponível em: <http://www.scielo.br/scielo.php?script=sci_arttext\&pi$\mathrm{d}=$ S2236-46332017000300307\&lng=en\&nrm=iso > Acesso em: 10 set, 2020.

GEHLEN, I. Identidade estigmatizada e cidadania excluída: a trajetória cabocla. In: ZARTH, Paulo A. et al. Os caminhos da exclusão social. Ijuí: UNIJUÍ, 1998.

HOFBAUER, A. Uma história de branqueamento ou o negro em questão. Dissertação (Mestrado em Filosofia, Letras e Ciências Humanas). Universidade de São Paulo. São Paulo: 1999.

HOFBAUER, A. O conceito de 'raça' e o ideário do 'branqueamento' no século XIX - Bases ideológicas do racismo brasileiro. Teoria e pesquisa. Revista de Ciência Política, São Carlos, v. 1, n. 42-SP: UFSCar, n. 42-43. 2013.

LE GOFF, J. História e memória. Campinas: Editora da UNICAMP, 1990.

LIMA, D. M. A construção histórica do termo caboclo: Sobre estruturas e representações sociais no meio rural amazônico. Novos Cadernos NAEA. v. 2, n. 2, mar. 2009. Disponível em: https://periodicos.ufpa.br/index.php/ncn/article/view/107. Acesso em: 23 out., 2020.

LIMA FILHO, V. M. Comércio de cabotagem e tráfico interno de escravos em Salvador (18301880). Revista Cantaneira. n.32. 2020. Disponível em: < https://periodicos.uff.br/cantareira / article/view/38260> Acesso em: 12 out., 2020.

MACHADO, P. P. Lideranças do contestado. Campinas: Ed. Unicamp, 2004.

MENDES, J. S. R. Desígnios da lei de terras: imigração, escravismo e propriedade fundiária no brasil império. Caderno CRH. Salvador. v. 22, n. 55, p. 173-184. 2009. Disponível em: $<$ https://www.scielo.br/pdf/ccrh/v22n55/11.pdf> Acesso em 08 Dez, 2020.

MONDARDO, M. L. Das migrações aos usos do território: caboclos, gaúchos e catarinenses no Sudoeste do Paraná. Unbral Fronteiras. 2007. Disponível em: http://unbral.nuvem.ufrgs. br/base/items/show/8811 Acesso em: 10 out., 2020.

MONDARDO, M. L. Os Caboclos no Sudoeste do Paraná: de uma "Sociedade Autárquica" a um grupo social excluído. Revista Eletrônica de História, UFGD -Dourados,v. 2, n. 3 jan./ jun. 2008. 
MONDARDO, M. L., O "lugar do futuro": a mobilidade gaúcha e catarinense e a (re)inveção do Sudoeste paranaense - 1940 à 1970. Unbral Fronteiras. 2010. Disponível em: http:/ / unbral. nuvem.ufrgs.br/base/items/show/9457. Acesso em: 18 set., 2020.

OBERG, K. Toledo: um município da fronteira oeste do Paraná. Rio de Janeiro: SSR, 1960.

OLIVEIRA, M. R. S. Leis abolicionistas: a história da abolição da escravatura no Brasil. In: BARBOZA, M. N. (Org.). Escravidão contemporânea. Brasília: MPF, 2017.

ORTIZ, R. Cultura brasileira e identidade nacional. 5. ed. São Paulo: Brasiliense, 2006.

PACE, R. Abusocientífico dotermo ‘caboclo’? Dúvidas de representação e autoridade. Bol.Mus. Para. Emílio Goeldi. Ciênc. hum. Belém, v. 1, n. 3, p. 79-92. 2006. Disponível em: http:/ /www. scielo.br/scielo.php?script $=$ sci_arttext\&pid $=$ S1981-81222006000300004\&lng $=$ en \&nrm $=\mathrm{i}-$ so. Acesso em: 22 set., 2020.

POCAI FILHO, R. Bichos do Mato: o sertão caboclo no sudoeste do Paraná. 2011. Disponível em: http://pt.scribd.com/rpocai/d/55446436-Bichos-do-Mato-O-sertao-caboclono-sudoeste-do-Parana. Acesso em: 15 fev., 2019.

POCAI FILHO, R. A saga do "pioneiro" no sertão dos "bichos do mato": A produção do espaço no Sudoeste do Paraná e o silêncio da História. Terra Plural. 2007. Disponível em: http://www.revistas2.uepg.br/index.php/tp/article/viewFile/5073/4361. Acesso em: 28 nov., 2019.

POCAI FILHO, R. Ecos no Vale do Chopim: Memórias e pertencimentos dos atingidos por barragens na comunidade de Nossa Senhora de Navegantes, Paraná. Anais do II Seminário Internacional História do Tempo Presente - UFSC. 2014. Disponível em: http:/ / eventos.udesc. br/ocs/index.php/STPII/tempopresente/paper/viewFile/66/24. Acesso em: 25 set., 2020.

POLI, J. Caboclo: pioneirismo e marginalização. Chapecó: Fundeste, 1991.

PRADO JÚNIOR, C. A questão agrária no Brasil. São Paulo: Brasiliense, 3. ed., 1981.

REICHERT, P. Diferenças culturais entre caboclos e teuto-brasileiros de Porto Novo. Universidade Federal do Rio Grande do Sul. Dissertação (Mestrado em Geografia). Porto Alegre: 2008. Disponível em: https://lume.ufrgs.br/handle/10183/13553. Acesso em: 11 out., 2020.

RENK, A. A colonização do oeste catarinense: as representações dos brasileiros. Cadernos do CEOM. v.5, n.1. 1991. Disponível em: < https://www.anpocs.com/index.php/encontros/ papers/22-encontro-anual-da-anpocs/gt-20/gt09-11/5101-arlenerenk-etnicidade/file> Acesso em 08 Dez, 2020.

RENK, A. A colonização do oeste catarinense: as representações dos brasileiros. In: Para uma história do oeste catarinense: 10 anos de CEOM. Chapecó: UNOESC, 1995.

RENK, A. Migrações: de ontem e de hoje. Chapecó: Grifos, 1999.

RENK, A. Narrativas da diferença. Chapecó: Argos, 2004.

RENK, A. A luta da erva: um ofício étnico no Oeste Catarinense. Chapecó: Argos, 2006.

RIBEIRO, D. O povo brasileiro: a formação e o sentido do Brasil. 3. ed. Paraná: Editora Global, 2015. 
SAHD, F.B. Tristes paralelos: apontamentos sobre a discriminação e desapropriação de nativos no Paraná e na palestina no século XX. XV Encontro regional de História - UEP. 2014. Disponível em: <http://www.erh2014.pr.anpuh.org/anais/2014/204.pdf> Acesso em 28 Nov. 2016.

SANTOS, R. A.; SILVA, R. M. N. B. Racismo científico no Brasil: um retrato racial do Brasil pós-escravatura. Educ. rev. v. 34, n. 68, p. 253-268. 2018. Disponível em: http://www.scielo.br/ scielo.php?script $=$ sci_arttext\&pid $=\mathrm{S} 0104-40602018000200253 \& \operatorname{lng}=\mathrm{en} \& \mathrm{nrm}=$ iso. Acesso em: 21 out., 2020.

SEYFERTH, G. As identidades dos imigrantes e o melting pot nacional. Horizontes Antropológicos.Porto Alegre. v.6, n. 14, p. 143-176. 2000. Disponível em: < https://www.scielo.br/pdf/ ha/v6n14/v6n14a07> Acesso em 08 Dez, 2020.

SEYFERTH, G. Colonização, imigração e a questão racial no brasil. Revista USP. n. 53, p. 117-149, 2002. Disponível em: http://www.revistas.usp.br/revusp/article/view/33192. Acesso em: 23 out., 2020.

SILVA, M. M. O caboclo no sudoeste do Paraná: sua identidade e memórias tombadas. Revista Semina, v. 11, n. 01, p. 1-8. 2012. Disponível em: http://seer.upf.br/index.php/ph/article/ view/4376/2870. Acesso em: 28, nov., 2016.

SKIDMORE, T. Preto no branco: raça e nacionalidade no pensamento brasileiro. Rio de Janeiro: Paz e Terra, 2012.

SOUZA, V.; SANTOS, R.V. O Congresso Universal de Raças, Londres, 1911: contextos, temas e debates. Boletim do Museu Paraense Emílio Goeldi. Ciências Humanas. v. 7, n. 3, p. 745-760, set.-dez. 2012.

SPIVAK, G. C. Can the Subaltern Speak?. In: GROSSBER, L. NELSON, C. (eds). Marxism and the Interpretation of Culture. London: Macmillan, 1988.

VENDRAME, M. I. O paraíso terrestre": alimentação como propaganda e construção da identidade italiana no sul do Brasil. RBHCS. v. 10, n. 20, jul-dez. 2018. Disponível em:

https://periodicos.furg.br/rbhcs/article/view/10794. Acesso em: 10 out., 2020.

WACHOWICZ, R. C. Obrageros, mensus e colonos: história do Oeste paranaense. Curitiba: Editora Vicentina, 1982.

WACHOWICZ, R. C. O camponês polonês no Brasil. Curitiba: Fundação Cultural Casa Romário Martins, 1981.

WACHOWICZ, R. Paraná, sudoeste: ocupação e colonização. Curitiba: Lítero Técnica, 1985.

WACHOWICZ, R. História do Paraná. Curitiba: Imprensa oficial do Paraná, 2001.

WITKOSKI, A. C. Terras, florestas e águas de trabalho: os camponeses amazônicos e as formas de uso de seus recursos naturais. 2. ed. São Paulo: Annablume, 2010.

ZARTH, P. Os caminhos da exclusão social. Ijuí: Editora Unijuí, 1998.

ZATTA, R. A colonização oficial do sudoeste paranaense e mito do "vazio demográfico. XV Encontro regional de História. UFPR. 2016. Disponível em: resources/anais/45/1466125179_ARQUIVO_TrabalhoAnpuhPR2016RonaldoZatta.pdf. Acesso em: 28, nov, 2019. 